\title{
CORRESPONDENCE
}

\section{Orang is man}

SIR - I have long resisted the temptation to point out the erroneous practice of many Western editors and authors of abbreviating 'orang' for 'orang-utan'. Reference to any Malay or Indonesian dictionary will confirm that 'orang' means 'man' and 'orang-utan' means 'orang-utan'. Therefore, when

Lowenstein, Molleson and Washburn reported that they have results to prove that 'both the Piltdown jaw and the canine tooth are those of an orang-utan' and you have their letter headlined "Piltdown jaw confirmed as orang" (Nature 23 September, p.294), I hope you are guilty only of misleading your readers with an inappropriate abbreviation and not of misunderstanding the key issue of the debate!

J. FLEURIS

Quebec, Canada

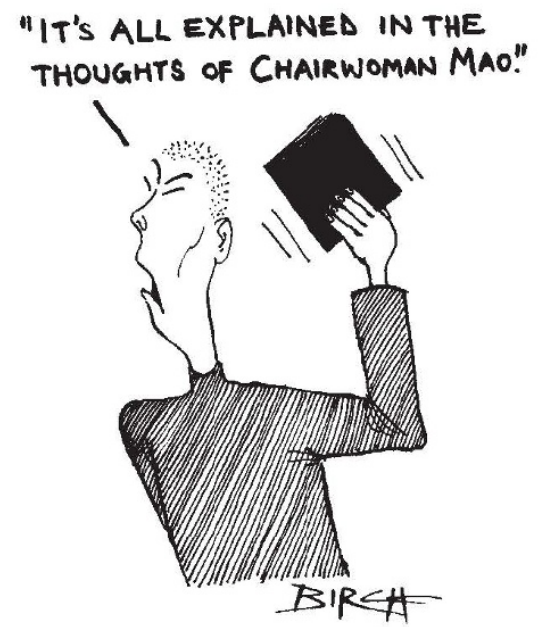

\section{Chinese puzzles}

SIR - In Nature of 16 September (p.200) J.A. Irving wrote to point out that Chinese surnames precede given names. This is no longer a problem in English translation because given names are now hyphenated and the second one is not capitalized. For foreigners, however, the gender of nouns and pronouns remains confusing. For instance, "Mr" Qi, cited by Irving, is actually Mrs Qi.

M.C. MCKENNA

American Museum of Natural History, New York,

New York, USA

\section{War prevention}

SIR - Jeffrey Segall (Nature 4 November, p.10) attributes to me (Nature 7 October, p.482) approval of the Medical Association for the Prevention of War (MAWP) proposals for a "Comprehensive ban on all methods and means of warfare specifically designed to kill or injure by inducing human disease". He fails to see two separate strands in my comments on MAWP.

Firstly, I consider the existing internationa] prohibitions and other restrictions on warfare as among the highest achievements of man.
We should all hope for a wider and more effective extension where appropriate of their type of international agreement. However, without diminishing their significance, it should be recognized that their success lies in that they involve noncentral areas of military concern.

Secondly, we should not restrict our attention only to the salient and direct causes of suffering involved in war. The concern with the methods and means of warfare should not distort our perception to ignore the fact that wars are initiated in the pursuit of military and political goals. And that prevention and control of these goals are as significant, if not more so, as that of their means for stopping war and the suffering within them.

Unfortunately not all desirable things are compatible. The inhibition of the initiation of wars depends largely on deterrence which requires armaments. The removal of the world's dependence on deterrence is likely to be achieved not by disarmament but by either an ascendancy of one of the superpowers to be effectively the only world power, or the creation of internal political structures of inhibition within military superpowers. But the latter and most desirable change would require the unlikely development of political pluralism, autonomous judiciary and intellectually open societies in the at present totalitarian powers of the Soviet Union and China.

J.R. SKOYLES

Hampstead,

London NW3, UK

\section{Malaria resurgence}

SIR - Chapin and Wasserstrom ${ }^{1}$ stated that resurgence of malaria in India was the result of the introduction of high yielding varieties (HYV) of rice and cotton, and we disputed the basic tenets of this hypothesis ${ }^{2}$. The main thrust of their argument now, however, seems to be that resurgence was the result of the use of insecticides in agriculture ${ }^{3}$. We would like to add a few further comments.

(1) Widespread resistance to common pesticides in anophelines developed during early and mid-1960s. Anopheles culicifacies was found resistant to DDT in 271 units in 14 states and to BHC in 24 units in 4 states. Similarly Anopheles stephensi was found resistant to DDT in 34 units in 5 states and to $\mathrm{BHC}$ in 6 units in 3 states $^{4}$.

(2) A. stephensi type form, the vector of urban malaria in India, breeds in cisterns, overhead tanks, garden tubs, fountain basins, disused containers, receptacles used for storing water, and other water accumulations in cities and does not breed in agricultural fields. Resurgence of malaria was observed in cities of India from southern, central and north India ${ }^{5}$.

(3) Although accurate quantities of DDT used in agriculture (1960-72) are not known, the available figures need not be extrapolated as they are about correct with minor variations.

(4) It is usual for genetic mutations for insecticide resistance to be less "fit", and reversion towards susceptibility generally occurs in the absence of insecticidal pressure. This was observed in $A$. culicifacies after withdrawal of spraying or change of insecticides in Maharashtra state in 12 units (28 villages $)^{4}$.

(5) Irrigation schemes contributed to the proliferation of the existing mosquito population which had become resistant in large parts of the country. It is incorrect to assume that the process of selection started de novo in the newly irrigated fields.

(6) In certain areas, a certain degree of contribution of the use of insecticide in agriculture in accelerating the pace of resistance in vectors of public health importance is understandable, and examples can be found to support this view. But it is difficult to believe that the massive quantities of insecticides used in public health and directed towards the malaria vectors were not the primary cause of widespread insecticide resistance.

The doubts raised by Chapin and Wasserstrom about the value of high-yielding crop varieties are a serious matter for a developing world striving hard to increase food production by introducing such varieties. The singling out of these crops as the main culprits for the resurgence of malaria without any authentic data is unjustified, and has been rightly condemned by Bruce-Chwatt as a "garbled account"6.

V.P. SHARMA

Malaria Research Centre (ICMR), Delhi,

India

K.N. MeHROTRA

Indian Agricultural Research Institute, New Delhi,

India

1. Chapin, G. \& Wasserstrom, S. Nature 293, 181-185(1981).

2. Sharma, V.P. \& Mehrotra, K.N. Nature 298, 210 (1982).

3. Wasserstrom, S. \& Chapin, G. Nature 299, 482 (1982).

4. Raghavan, N.G.S. et al. Buil. Ind. Soc. Malar. com. Dis. 4, 209-245 (1969).

Pattanayak, S. et al. Ind. J. Matar. 18, 21-27 (1981).

6. Bruce-('hwatt, L.J. Nature 294, 302 (1981)

\section{Muscling in}

$\mathrm{SIR}-$ It is very misleading for muscle biophysicists to continue to refer to the anterior byssal retractor muscle (ABRM) of Mytilus as an example of unstriated (= smooth) muscle (Nature 299, 308; 1980). For almost 30 years, since the ABRM was first examined by electron microscopy, it has been realized that this muscle in fact enjoys a very regular, striated, ultrastructure. There is a highly orderly arrangement of thin and thick filaments, although they are arranged obliquely rather than transversely, in the relaxed muscle. The correct designation for this type of muscle is obliquely-striated.

Graham Hoyle

University of Oregon,

Eugene,

Oregon, USA 